\title{
Premorbid Personality and the Risk of Parkinson's Disease
}

\author{
Kelly L. Sullivan ${ }^{\mathrm{a}, \mathrm{b}, \mathrm{d}}$, James A. Mortimer ${ }^{\mathrm{a}}$, Wei Wang ${ }^{\mathrm{a}}$, Theresa A. Zesiewicz \\ H. James Brownlee Jrc ${ }^{\mathrm{c}}$, Amy R. Borenstein ${ }^{\mathrm{a}}$
}

\begin{abstract}
Background: Previous studies support the hypothesis that premorbid personality characteristics may be associated with the risk of Parkinson's disease (PD). However, most of these relied upon subjective reports of premorbid personality earlier in life, which may be subject to recall bias. The objective of the current study was to evaluate the association of PD with risk-taking, routinization, smoking and alcohol consumption in early-adult life as indicators of premorbid personality.
\end{abstract}

Methods: In-person interviews were conducted with 89 PD patients and 99 controls from a university-based medical center. Associations between indicators of early-adult personality and risk of PD were examined using logistic regression.

Results: Adjusting for age, sex and education, taking or wanting to take more activity risks as a young adult was inversely associated with the risk of PD in the entire sample (odds ratio $(\mathrm{OR})=0.78$ ( $95 \%$ confidence interval (CI) 0.63 - 0.97)). Among women, higher levels of routinization as a young adult were associated with an increased risk of $\mathrm{PD}(\mathrm{OR}=1.63(95 \% \mathrm{CI} 1.05-2.53))$.

Conclusions: Parkinson patients were more likely to take or want to take fewer risks in early-adult life and to prefer a more routine lifestyle than controls, suggesting that individuals with PD may have distinctive premorbid personality characteristics.

Keywords: Novelty-seeking; Routinization; Risk-taking; Premorbid; Risk factors

Manuscript accepted for publication June 25, 2014

${ }^{a}$ Department of Epidemiology and Biostatistics, College of Public Health, University of South Florida, Tampa, FL, USA

${ }^{b}$ Department of Neurology, College of Medicine, University of South

Florida, Tampa, FL, USA

${ }^{\mathrm{c}}$ Department of Family Medicine, College of Medicine, University of South Florida, Tampa, FL, USA

${ }^{\mathrm{d}}$ Corresponding Author: Kelly Sullivan, University of South Florida, 12901 Bruce B. Downs Blvd., MDC 55, Tampa, FL 33612, USA.

Email:kbarber@health.usf.edu

doi: http://dx.doi.org/10.14740/jnr281w

\section{Introduction}

In the companion paper [1], we showed that engagement or desired engagement in risky activities before the age of 35 was positively correlated with current levels of novelty-seeking and inversely correlated with current levels of harm-avoidance in cases as well as in controls. Likewise, young-adult routinization was inversely correlated with novelty-seeking and positively correlated with harm-avoidance in both cases and controls. These findings indicate the stability of personality traits in Parkinson's disease (PD) and support their assessment as possible non-motor indicators of the disease.

Case-control studies examining premorbid personality have found that PD patients had reduced leadership tendencies, flexibility and sociability and were more quiet, generous, cautious, introverted, rigid, socially conforming and even-tempered during the time period prior to the onset of PD compared with controls [2-8]. However, other studies failed to find an association between premorbid personality measures and PD $[9,10]$. Many of the previous studies were limited by small sample size [2, 3, 5-7, 10-12], use of proxies to report personality $[3,10]$ and potential for recall bias resulting from the use of subjective personality assessments in prevalent cases [2-7, 10-15]. The objective of the current study was to evaluate the association of premorbid personality indicators in earlier adult life, including participation or desired participation in risky activities, preference for a routine lifestyle, and cigarette and alcohol consumption, with the risk of PD.

\section{Methods}

\section{Subjects}

Subject selection and participation have been fully detailed previously [1]. Briefly, cases were recruited from a Movement Disorders Clinic and controls from a Family Medicine Clinic at the University of South Florida. Potential subjects were contacted by mail and then by telephone to screen and 


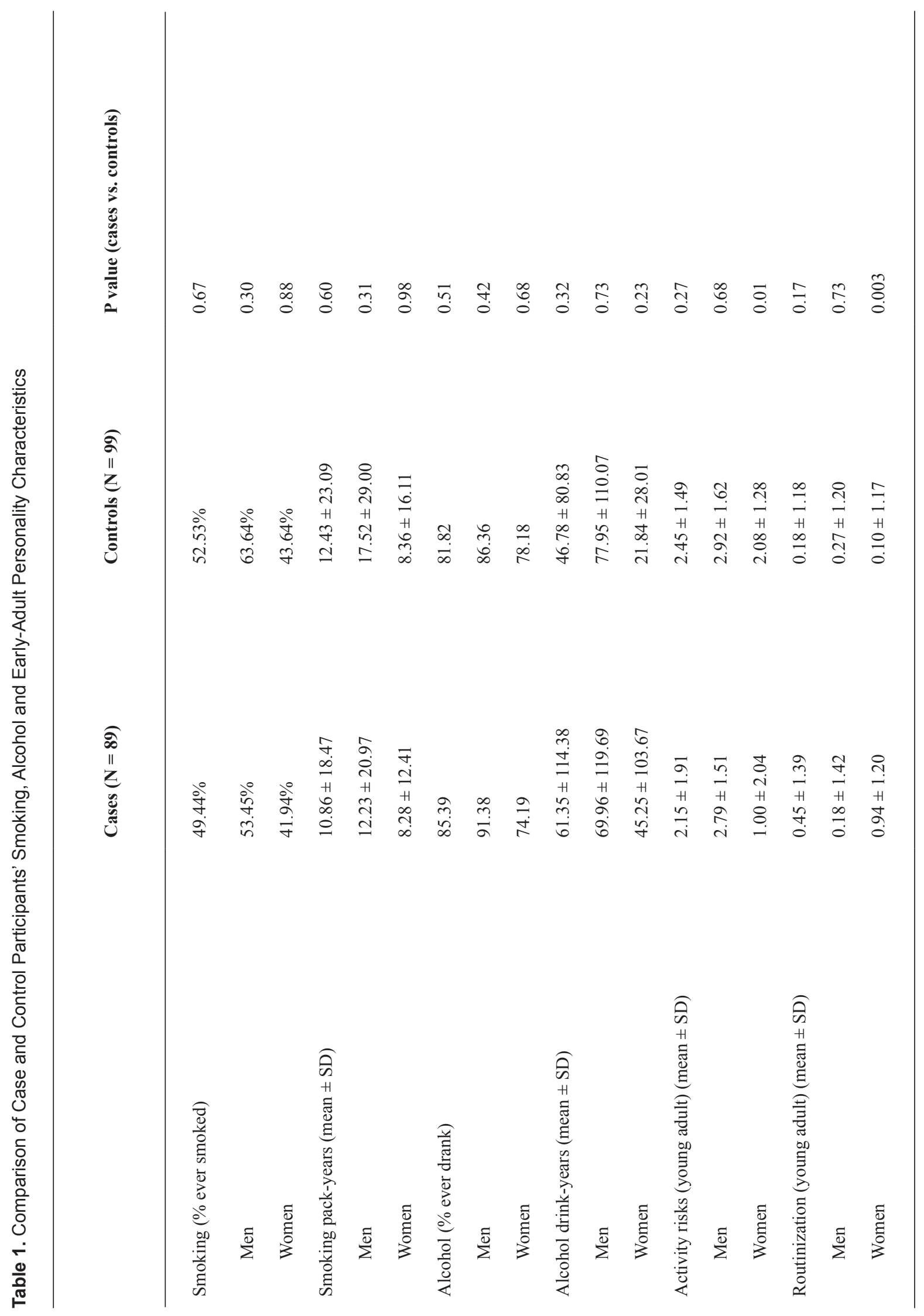


recruit them. Eligibility criteria required subjects to be aged 50 - 80 years, Caucasian, free from memory impairment, and able to read and speak English. Cases were ineligible if they had a diagnosis of atypical PD, a history of neurosurgery for $\mathrm{PD}$, or severe motor fluctuations. The protocol and questionnaires were approved by the University of South Florida's Institutional Review Board and all subjects gave written informed consent prior to the commencement of data collection.

\section{Exposure assessments}

Trained interviewers used highly structured questionnaires to complete in-person assessment of subjects at the study site (medical clinic) in private settings. Indicators of premorbid personality included past risk-taking behaviors, routinization, smoking and alcohol consumption before age 35 . These indicators were assessed with questionnaires developed by the study team and are described in the companion article [1].

\section{Covariates}

Age, sex and years of formal education were also assessed during the study interview.

\section{Statistical methods}

Factor loadings from a principal components factor analysis were used to create latent variables representing earlyadult (less than age 35 years) risk-taking and routinization as previously described [1]. The association of early-adult life risk-taking activities, routinization and smoking and alcohol consumption with the risk of PD was assessed through unconditional logistic regression analysis, adjusted for age, sex and education. The odds ratios (ORs) and 95\% confidence intervals (CIs) for PD associated with smoking and alcohol consumption were constructed to reflect units of 10 packyears of smoking and 10-year drink-years.

Because men and women might have had different opportunities to participate in certain activities, we also conducted analyses stratified by sex. $\mathrm{P}$ values less than 0.05 (two-sided test) were interpreted as being statistically significant. All data were analyzed using SAS version 9.2 [16].

\section{Results}

Recruitment and participation details have been detailed in the companion article [1]. A total of 99 cases and 89 controls completed study assessments. Although there was no difference in mean age between cases and controls $(P=0.29)$, there was a significantly greater proportion of men among cases $(65.2 \%$ of cases vs. $44.4 \%$ of controls; $\mathrm{P}=0.005)$. Cas- es also completed approximately 1.5 fewer years of formal education than controls $(\mathrm{P}=0.003)$.

Characteristics of participants' early-adult personality and smoking and alcohol consumption are shown in Table 1. The proportion of subjects who had ever smoked cigarettes (49\% of cases and $53 \%$ of controls) or drank alcohol $(85 \%$ of cases and $82 \%$ of controls) did not differ between cases and controls $(\mathrm{P}=0.67$ and $\mathrm{P}=0.51$, respectively, [1]), nor did the number of pack-years (mean $\pm \mathrm{SD}$ for cases: $10.86 \pm 18.47$ pack-years; mean for controls: $12.43 \pm 23.09$ pack-years; $\mathrm{P}$ $=0.60$ ) or drink-years (mean $\pm \mathrm{SD}$ for cases: $61.35 \pm 114.38$ drink years; mean for controls: $46.78 \pm 80.83$ drink years; $\mathrm{P}$ $=0.32$ ). Significant differences were seen among women for both activity risks and preferences for more routinization as young adults.

In logistic regression analyses adjusted for age, sex and education, taking and wanting to take more activity risks as a young adult was inversely associated with the risk of PD in the total sample $(\mathrm{OR}=0.78(95 \%$ CI $0.63-0.97))$ and among women $(\mathrm{OR}=0.69$ (95\% CI 0.50 - 0.95)) (Table 2). The adjusted risk of $\mathrm{PD}$ among men who reported taking activity risks as a young adult was also reduced $(\mathrm{OR}=0.88$ (95\% CI 0.66 - 1.19)), but was not statistically significant. Among women but not men, a higher degree of routinization was associated with a higher risk of PD $(\mathrm{OR}=1.63(95 \% \mathrm{CI}$ $1.05-2.53))$.

Neither history of ever-smoking (OR for total sample $=$ 0.67 (95\% CI 0.36 - 1.25)) nor pack-years of smoking was statistically associated with PD (OR $=0.90$ (95\% CI 0.77 1.04)) adjusting for age, sex and education. In addition, there was no association with alcohol use.

When activity risks, routinization, pack-years of smoking, drink-years of alcohol consumption, age, sex and education were entered together (Table 2), young adult risk-taking remained significantly associated with $\mathrm{PD}$.

\section{Discussion}

In this study of 89 PD cases and 99 clinic-based controls, taking or wanting to take more risks as a young adult was associated with a decreased risk of PD in the entire sample and among women. Women who reported greater preference for routinization as a young adult were also at increased risk for PD. Neither pack-years of smoking nor drink-years of alcohol were associated with risk of PD in our sample. The significant association of risk-taking as a young adult with PD remained when other personality indicators were included in the model.

Relatively little information is available from previous studies on sex differences in personality or psychiatric conditions preceding onset of PD. In a historical cohort study [17] men with PD were more likely to be diagnosed or treated for depression or anxiety compared with controls [14] 


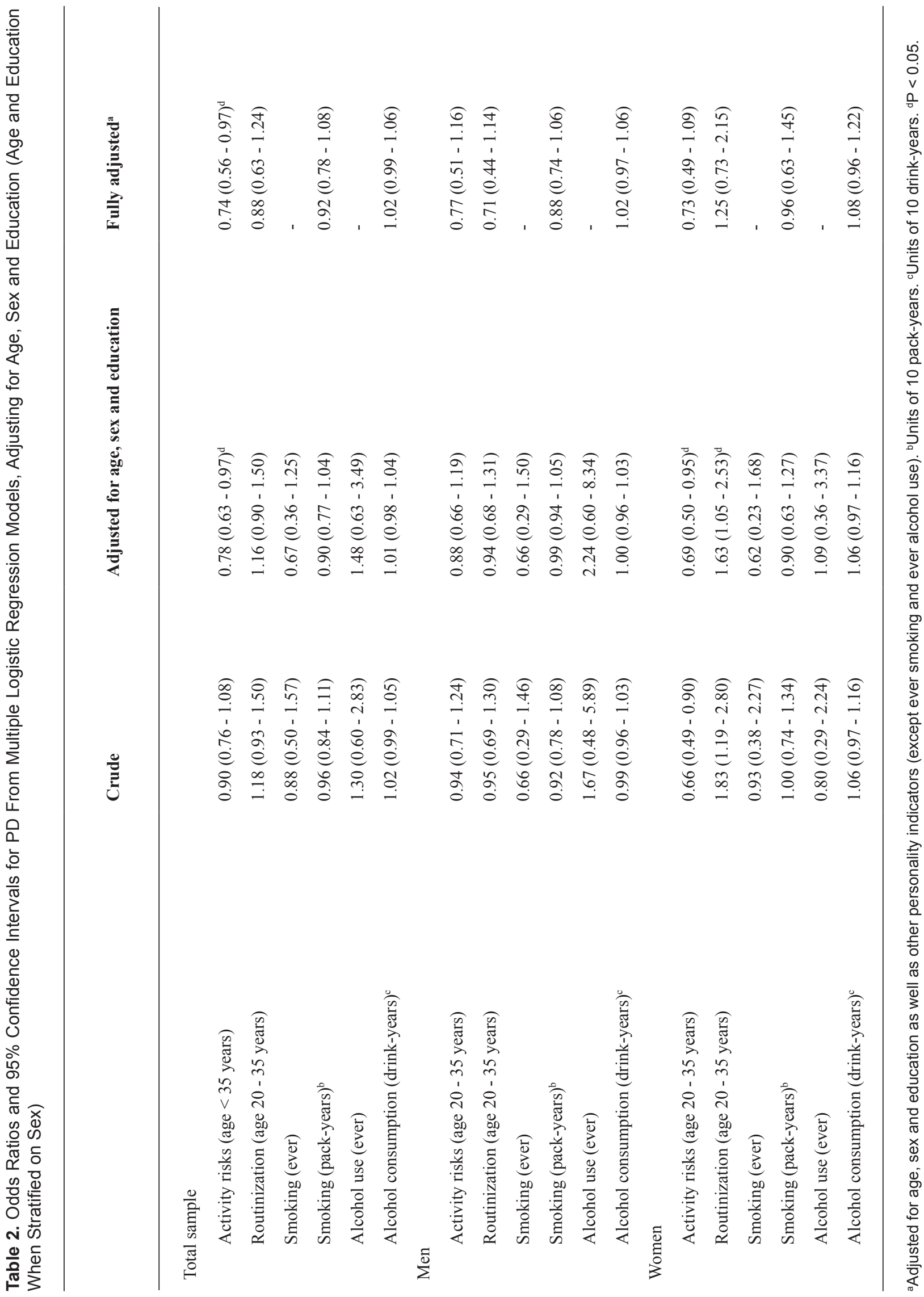


and to have a greater likelihood of anxiety [17], while there was no difference for depression or anxiety among women. However, a small case-control study found that women with PD have an increased risk of hypochondria, depression, hysteria and social introversion as measured by the Minnesota Multiphasic Personality Inventory (MMPI) while there were no psychiatric or personality differences among male cases compared with controls [11]. In contrast, Arabia's historical cohort study [9] found similar results in men and women on MMPI measures of sensation-seeking, hypomania and positive emotionality.

Previous epidemiologic studies, including several meta-analyses, have demonstrated that smoking, caffeine and alcohol intake are inversely associated with the risk of PD [18-26]. Results from a pooled analysis of 2,328 cases and 4,113 controls [22] showed a lower risk of PD in ever-smokers $(\mathrm{OR}=0.70(95 \%$ CI $0.63-0.78))$. Our findings were consistent with the pooled case-control results with regard to the point estimate (OR for smoking history $=0.67(95 \% \mathrm{CI}$ $0.36-1.25)$ ); the lack of statistical significance in our smoking findings may be due to the relatively small sample size. Pack-years of smoking was lower in our sample among both cases $($ mean $=10.86 \pm 18.47)$ and controls $($ mean $=12.43 \pm$ 23.09) compared with previous reports (range of mean values in previous studies: 16 - 46) [22]; the high educational level of our sample might account for this difference. Other meta-analyses have shown that smoking as well as caffeine and alcohol intake is inversely associated with PD risk [1826] and it has been theorized that nicotine may be neuroprotective [27]. Two explanations of the inverse association between smoking and PD must be considered: 1) smoking increases striatal dopamine transporter activity [28], increases levels of vesicular dopamine receptors [28], reduces the loss of dopaminergic neurons in the substantia nigra [29], and stimulates dopamine release [30-32], possibly through its inhibition of monoamine oxidase [33-35] which catabolizes dopamine [36], and/or 2) the reward system of the brain may differ in individuals who are destined to develop PD, resulting in a reduction in voluntary exposure to smoking. Although our observations related to pack-years of smoking did not show significant differences, cases in our study reported fewer pack-years of smoking compared with controls and this difference was more pronounced among men. In the pooled analysis described above similar results were reported for men $(\mathrm{OR}=0.74(95 \% \mathrm{CI} 0.64-0.86))$ and women $(0.61$ $(0.51-0.72))$ with regard to ever vs. never smoking [22]. These point estimates are comparable to our findings among men $(\mathrm{OR}=0.66(0.29-1.50))$ and women $(\mathrm{OR}=0.62(0.23$ - 1.68)), although our relatively small sample size likely resulted in wider CIs precluding statistical significance.

Previous studies of premorbid personality in PD have yielded inconsistent results [2-10]. The validity of results from studies that rely on subjective retrospective measures of personality is questionable as this assessment may be lim- ited by the potential for recall bias associated with having a chronic disease. To examine the temporal sequence of the association between risk-taking and PD and to exclude the possibility of recall bias in the evaluation of results, assessment of personality should be performed as distally as possible from the onset of PD and preferentially prospectively. The Mayo Clinic Cohort Study of Personality and Aging [9, 37] included 7,216 subjects from Olmsted County, Minnesota who completed the MMPI as young adults (aged 20 39 years). During a follow-up period with a median of 29.2 years, 156 subjects developed PD. The risk of PD was associated with increased neuroticism as a young adult (hazard ratio $(\mathrm{HR})=1.54(95 \% \mathrm{CI} 1.10-2.16))$ and higher scores in anxiety $(\mathrm{HR}=1.63(95 \% \mathrm{CI} 1.16-2.27)$ ) [37]. There was no difference in levels of sensation-seeking, hypomania, positive emotionality, social introversion or constraint among subjects who developed PD compared to those who remained free from PD [9].

Another approach has been to study twins who are discordant for the disease $[2,5,12]$ and to compare personality characteristics between affected and unaffected twins. Heberlein et al used a semi-structured interview to evaluate premorbid lifestyle and activities that may be influenced by subjects' personalities such as hobbies, education, friendship and travel [2]. There were no differences in history of these activities, although the sample was small ( $\mathrm{n}=15$ twin pairs). Another study of twins discordant for PD reported that the twin with PD was less often in a leadership role, less aggressive, less confident, less light-hearted, and more nervous, quiet, and self-controlled compared to the twin without the disease, and these differences were present 10 years prior to the onset of PD [5]. In addition, twins with PD smoked significantly fewer cigarettes than their unaffected siblings [5]. Duvoisin et al [12] examined 12 twin pairs discordant for PD and reported indications of personality differences as early as adolescence, although these differences were not evaluated statistically.

An important strength of the current study was the use of activities and habits as indicators of premorbid personality. Although these evaluations were retrospective and also could be subject to recall bias, it is less likely that cases and controls would recall activities and habits differently due to influences of PD, compared to recall of premorbid personality characteristics. The small sample size was a limitation of this study and may have contributed to the failure to find differences that might have reached statistical significance in a larger sample (e.g., between ever-smoking and risk of PD).

The finding of an increased risk of PD among those with lower risk-taking tendencies in earlier adult life is consistent with association of this characteristic with harm-avoidance and neuroticism in later life [1], the most commonly reported features of the personality of Parkinson patients [13, 15, 3739]. The present findings suggest that personality characteristics in earlier life manifested by fewer risk-taking behav- 
iors and preferences for a predictable routine lifestyle may be useful in the identification of individuals at higher risk of PD.

\section{Disclosure}

No disclosures to report.

\section{References}

1. Sullivan KL, Mortimer J, Wang W, Zesiewicz TA, Brownlee HJ, Borenstein AR. Early-adult life correlates of personality in Parkinson's disease. J Neurol Res. 2014;4(2-3):51-62.

2. Heberlein I, Ludin HP, Scholz J, Vieregge P. Personality, depression, and premorbid lifestyle in twin pairs discordant for Parkinson's disease. J Neurol Neurosurg Psychiatry. 1998;64(2):262-266.

3. Hubble JP, Venkatesh R, Hassanein RE, Gray C, Koller WC. Personality and depression in Parkinson's disease. J Nerv Ment Dis. 1993;181(11):657-662.

4. Watanabe K. [A case-control study of Parkinson's disease]. Nihon Koshu Eisei Zasshi. 1994;41(1):22-33.

5. Ward CD, Duvoisin RC, Ince SE, Nutt JD, Eldridge R, Calne DB, Dambrosia J. Parkinson's disease in twins. Adv Neurol. 1984;40:341-344.

6. Poewe W, Karamat E, Kemmler GW, Gerstenbrand F. The premorbid personality of patients with Parkinson's disease: a comparative study with healthy controls and patients with essential tremor. Adv Neurol. 1990;53:339342.

7. Eatough VM, Kempster PA, Stern GM, Lees AJ. Premorbid personality and idiopathic Parkinson's disease. Adv Neurol. 1990;53:335-337.

8. Poewe W, Gerstenbrand F, Ransmayr G, Plorer S. Premorbid personality of Parkinson patients. J Neural Transm Suppl. 1983;19:215-224.

9. Arabia G, Grossardt BR, Colligan RC, Bower JH, Maraganore DM, Ahlskog JE, Geda YE, et al. Novelty seeking and introversion do not predict the long-term risk of Parkinson disease. Neurology. 2010;75(4):349-357.

10. Glosser G, Clark C, Freundlich B, Kliner-Krenzel L, Flaherty P, Stern M. A controlled investigation of current and premorbid personality: characteristics of Parkinson's disease patients. Mov Disord. 1995;10(2):201206.

11. Jimenez-Jimenez FJ, Santos J, Zancada F, Molina JA, Irastorza J, Fernandez-Ballesteros A, Roldan A. "Premorbid" personality of patients with Parkinson's disease. Acta Neurol (Napoli). 1992;14(3):208-214.

12. Duvoisin RC, Eldridge R, Williams A, Nutt J, Calne D. Twin study of Parkinson disease. Neurology.
1981;31(1):77-80.

13. Fujii C, Harada S, Ohkoshi N, Hayashi A, Yoshizawa K. Cross-cultural traits for personality of patients with Parkinson's disease in Japan. Am J Med Genet. 2000;96(1):1-3.

14. Jacobs H, Heberlein I, Vieregge A, Vieregge P. Personality traits in young patients with Parkinson's disease. Acta Neurol Scand. 2001;103(2):82-87.

15. Kaasinen V, Nurmi E, Bergman J, Eskola O, Solin O, Sonninen P, Rinne JO. Personality traits and brain dopaminergic function in Parkinson's disease. Proc Natl Acad Sci U S A. 2001;98(23):13272-13277.

16. SAS 9.2. Cary, NC: SAS Institute Inc. 2008.

17. Bower JH, G.B., Maraganore DM, Ahlskog JE, de Andrade M, Rocca WA, The Mayo Clinic Cohort Study of Personality and Aging: Results for Parkinson's disease. Neurology. 2005;64(Suppl 1):A282-A283.

18. Benedetti MD, Bower JH, Maraganore DM, McDonnell SK, Peterson BJ, Ahlskog JE, Schaid DJ, et al. Smoking, alcohol, and coffee consumption preceding Parkinson's disease: a case-control study. Neurology. 2000;55(9):1350-1358.

19. Gorell JM, Rybicki BA, Johnson CC, Peterson EL. Smoking and Parkinson's disease: a dose-response relationship. Neurology. 1999;52(1):115-119.

20. Hellenbrand W, Seidler A, Robra BP, Vieregge P, Oertel WH, Joerg J, Nischan P, et al. Smoking and Parkinson's disease: a case-control study in Germany. Int J Epidemiol. 1997;26(2):328-339.

21. Sugita M, Izuno T, Tatemichi M, Otahara Y. Metaanalysis for epidemiologic studies on the relationship between smoking and Parkinson's disease. J Epidemiol. 2001;11(2):87-94.

22. Ritz B, Ascherio A, Checkoway H, Marder KS, Nelson LM, Rocca WA, Ross GW, et al. Pooled analysis of tobacco use and risk of Parkinson disease. Arch Neurol. 2007;64(7):990-997.

23. Checkoway H, Powers K, Smith-Weller T, Franklin GM, Longstreth WT, Jr., Swanson PD. Parkinson's disease risks associated with cigarette smoking, alcohol consumption, and caffeine intake. Am J Epidemiol. 2002;155(8):732-738.

24. Hernan MA, Takkouche B, Caamano-Isorna F, GestalOtero JJ. A meta-analysis of coffee drinking, cigarette smoking, and the risk of Parkinson's disease. Ann Neurol. 2002;52(3):276-284.

25. Evans AH, Lawrence AD, Potts J, MacGregor L, Katzenschlager R, Shaw K, Zijlmans J, et al. Relationship between impulsive sensation seeking traits, smoking, alcohol and caffeine intake, and Parkinson's disease. J Neurol Neurosurg Psychiatry. 2006;77(3):317-321.

26. Allam MF, Campbell MJ, Hofman A, Del Castillo AS, Fernandez-Crehuet Navajas R. Smoking and Parkinson's disease: systematic review of prospective studies. 
Mov Disord. 2004;19(6):614-621.

27. Ross GW, Petrovitch H. Current evidence for neuroprotective effects of nicotine and caffeine against Parkinson's disease. Drugs Aging. 2001;18(11):797-806.

28. Quik M, Parameswaran N, McCallum SE, Bordia T, Bao S, McCormack A, Kim A, et al. Chronic oral nicotine treatment protects against striatal degeneration in MPTPtreated primates. J Neurochem. 2006;98(6):1866-1875.

29. Parain K, Hapdey C, Rousselet E, Marchand V, Dumery B, Hirsch EC. Cigarette smoke and nicotine protect dopaminergic neurons against the 1-methyl-4-phenyl1,2,3,6-tetrahydropyridine Parkinsonian toxin. Brain Res. 2003;984(1-2):224-232.

30. Janson AM, Fuxe K, Goldstein M. Differential effects of acute and chronic nicotine treatment on MPTP-(1methyl-4-phenyl-1,2,3,6-tetrahydropyridine) induced degeneration of nigrostriatal dopamine neurons in the black mouse. Clin Investig. 1992;70(3-4):232-238.

31. Westfall TC, F.R., Fudger MF, Clark WG. Effect of nicotine and related substance upon amine levels in the brain. Ann NY Acad Sci. 1967;142:83-100.

32. Clarke PB, Hommer DW, Pert A, Skirboll LR. Electrophysiological actions of nicotine on substantia nigra single units. Br J Pharmacol. 1985;85(4):827-835.

33. Fowler JS, Volkow ND, Wang GJ, Pappas N, Logan J, MacGregor R, Alexoff D, et al. Inhibition of mono- amine oxidase $\mathrm{B}$ in the brains of smokers. Nature. 1996;379(6567):733-736.

34. Fowler JS, Volkow ND, Wang GJ, Pappas N, Logan J, Shea C, Alexoff D, et al. Brain monoamine oxidase A inhibition in cigarette smokers. Proc Natl Acad Sci U S A. 1996;93(24):14065-14069.

35. Fowler JS, W.G., Volkow ND, Franceschi D, Logan J, Pappas N, Shea C, MacGregor RR, Garza V. Smoking a single cigarette does not produce a measurable reduction in brain MAO B in non-smokers. Am J Psychiartry. 2000;157(11):1864-1866.

36. Riederer P, Konradi C, Hebenstreit G, Youdim MB. Neurochemical perspectives to the function of monoamine oxidase. Acta Neurol Scand Suppl. 1989;126:41-45.

37. Bower JH, Grossardt BR, Maraganore DM, Ahlskog JE, Colligan RC, Geda YE, Therneau TM, et al. Anxious personality predicts an increased risk of Parkinson's disease. Mov Disord. 2010;25(13):2105-2113.

38. McNamara P, Durso R, Harris E. Alterations of the sense of self and personality in Parkinson's disease. Int J Geriatr Psychiatry. 2008;23(1):79-84.

39. Ishihara-Paul L, Wainwright NW, Khaw KT, Luben RN, Welch AA, Day NE, Brayne C, et al. Prospective association between emotional health and clinical evidence of Parkinson's disease. Eur J Neurol. 2008;15(11):11481154. 